\title{
An integrated methodology for the modeling of Fluid Catalytic Cracking (FCC) riser reactor
}

\author{
Yu Peng Du $\cdot$ Qi Yang $\cdot$ Hui Zhao \\ Chao He Yang
}

Received: 5 June 2014/ Accepted: 30 July 2014/Published online: 12 September 2014

(c) The Author(s) 2014. This article is published with open access at Springerlink.com

\begin{abstract}
Modeling description of the riser reactor is a highly interesting issue in the development of FCC process. However, one of the challenging problems in the modeling of FCC riser reactors is that sophisticated flow-reaction models with high accuracy need long computational time, while simple flow-reaction models give rise to results with fast computation but low accuracy. This dilemma requires new type of coupled flow-reaction models. The goal of this study was to propose a novel integrated model with timeefficient computation and acceptable accuracy. The integrated model, named equivalent reactor network (ERN) model, was established based on Aspen Plus simulator with considering gas-solid hydrodynamics via built-in modules and catalytic reactions via external FORTRAN subroutines, as well as lump mixtures characterized by real components. Through comparing with pilot-scale experimental data and industrial plant data in two case studies, the developed ERN model was justified to be capable of precisely and quickly modeling FCC riser reactors. Furthermore, the proposed methodology is expected to be readily applied to studies on the dynamic simulation, optimization, and control of FCC units in future studies.
\end{abstract}

Keywords Equivalent reactor network (ERN) - Aspen plus - Riser reactor - FORTRAN subroutine - Integrated model

Y. P. Du · Q. Yang · H. Zhao · C. H. Yang $(\bowtie)$

State Key Laboratory of Heavy Oil Processing,

China University of Petroleum, Qingdao 266580,

The People's Republic of China (PRC)

e-mail: yangch@upc.edu.com

\section{Introduction}

Fluid catalytic cracking (FCC) is a key and widely used refinery process for converting heavy oil to valuable vehicle fuel such as gasoline and diesel, as well as maximizing light olefin production. The riser reactor, always operating at the fast-fluidized bed regime in terms of hydrodynamics, should be one of the most complex parts of FCC units concerning intricate two-phase or even three-phase flow behaviors and complicated catalytic cracking reactions occurring in it. Therefore, modeling description of the riser reactor becomes a highly interesting issue in the development of FCC process [1].

Most of the work on modeling the FCC riser reactors was focused on either reactor hydrodynamics or catalytic cracking kinetics. Generally, the fluid flow models could be classified into three categories [2]: (i) 1-D models, normally with simplified formulation and solution; (ii) semiempirical 2-D models, usually described as core-annulus models; and (iii) computational fluid dynamics (CFD) models deduced from phenomenological concepts with a comprehensive and generic character but not easy to formulate and solve. Regarding the catalytic reaction kinetics, mathematical models might also be divided into three types [3]: (i) empirical correlation models; (ii) lumped kinetic models; and (iii) molecular level kinetic models. Combining different fluid flow models (i.e. hydrodynamics model) with varying chemical reaction models (i.e. kinetic model) gives rise to coupled flow-reaction models for FCC riser reactors. Hitherto, five categories of coupled flowreaction models are commonly used in either academic or industrial investigations. Table 1 lists main features and applications of these models. As indicated in Table 1 each kind of coupled flow-reaction model has its own advantages and disadvantages. Specifically, while sophisticated flow-reaction models with high accuracy require long 
Table 1 Main features and applications of conventional flow-reaction models for FCC riser reactors

\begin{tabular}{|c|c|c|c|}
\hline Categories & Flow-reaction models & Main features and applications & References \\
\hline 1 & $\begin{array}{l}\text { 1D hydrodynamics }+ \text { lumped } \\
\text { kinetics }\end{array}$ & $\begin{array}{l}\text { Main feature: Model is simple, easy to solve, but with relatively low accuracy } \\
\text { Application (i): Study on specific catalytic cracking phenomena, such as kinetic } \\
\text { models and catalyst deactivation models } \\
\text { Application (ii): Simulation of riser reactors in the process of steady and unsteady } \\
\text { analysis, control and optimization of FCCU }\end{array}$ & {$[7,8]$} \\
\hline 2 & $\begin{array}{l}\text { 1D } \\
\text { hydrodynamics }+ \text { molecular } \\
\text { level kinetics }\end{array}$ & $\begin{array}{l}\text { Main feature: Kinetics is complicated, needs a great deal of instrumental analysis data } \\
\text { Application: Developing molecular level kinetic models }\end{array}$ & {$[9,10]$} \\
\hline 3 & $\begin{array}{l}2 \mathrm{D} \text { empirical } \\
\text { hydrodynamics }+ \text { lumped } \\
\text { kinetics }\end{array}$ & $\begin{array}{l}\text { Main feature: Computational time and precision are acceptable, but quite empirical } \\
\text { Application (i): Reactor simulation and design } \\
\text { Application (ii): Phenomenological studies on physical problems, such as the effect of } \\
\text { feed nozzles and oil droplets vaporization on reactor's performance }\end{array}$ & {$[11,12]$} \\
\hline 4 & CFD + lumped kinetics & $\begin{array}{l}\text { Main feature: Comprehensive and informative, with high accuracy but long } \\
\text { computational period } \\
\text { Application (i): Reactor design and simulation } \\
\text { Application (ii): Phenomenological studies of the physical problem, and deep insights } \\
\text { into mass transfer, momentum transfer, heat transfer under reaction conditions }\end{array}$ & {$[4-6]$} \\
\hline 5 & $\begin{array}{l}\text { CFD }+ \text { molecular level } \\
\text { kinetics }\end{array}$ & $\begin{array}{l}\text { Main feature: Most complicated model to solve, but benefits deep understanding of } \\
\text { FCC process } \\
\text { Application: Modeling of riser reactors }\end{array}$ & [13] \\
\hline
\end{tabular}

computational time, simple coupled flow-reaction models give rise to results with efficient computation but low accuracy. This point can be best illustrated with the example of CFD models coupled to the flow-reaction models (e.g. the 4th-category models in Table 1), highly detailed flow field structures can readily be obtained with CFD models. Such detail, however, requires quite a lot of computational efforts and time-consuming simulations, resulting in low accessibility in real-time dynamic simulation process [4-6]. On the other hand, the assumption of plug flow in riser reactors (e.g. the 1st-category models in Table 1), which was commonly accepted in dynamic modeling and optimization studies of FCC units, could not fully describe the real hydrodynamic behavior inside the riser as the back-mixing was always neglected in this assumption [1, 7, 8]. Aiming at the challenging problem, developing new flow-reaction models with high accuracy and short computational period is necessary to the modeling of FCC riser reactors, especially in the case of dynamic modeling, optimization, and control of FCC units.

Based on this demand, the main objective of the present study was to propose a novel integrated model named Equivalent Reactor Network (ERN) model constructed in Aspen Plus simulator for FCC riser modeling work. The present study focuses on the construction procedure of the integrated ERN model and validations of the proposed model through comparing model predictions with available experiment data and industrial plant data reported in literature.

\section{Methodology}

Hydrodynamics model—variable superficial velocity model [14]

Since the catalytic cracking of hydrocarbons is a process with expanding mole number of species, volumetric flow rate of oil vapor in a FCC riser reactor increases all along the riser height. That is to say, the gas velocity varies all the time at various axial positions. For the purpose of adequately describing such kind of phenomenon, a variable superficial velocity hydrodynamic model [14] is adopted herein.

Assumptions of the developed gas-solid hydrodynamic model for the FCC riser reactor were summarized as follows [14]:

1. Within the given ranges of gaseous superficial velocity $\left(U_{0}\right)$ and solid circulation flux $\left(G_{\mathrm{s}}\right)$, a core-annulus flow mode was observed.

2. The riser reactor is vertically divided into two regions: the acceleration region and the fully developed region.

3. Gaseous superficial velocity $\left(U_{0}\right)$ increases along the riser height (see Eq. 1), corresponding to the production of gaseous products.

$U_{0}=u_{0}+\lg (1+7 x / H) u_{0}$

where $u_{0}$ is the initial gaseous velocity at the riser inlet and $x$ is the axial position along the riser height. 
Table 2 List of primary hydrodynamics model equations

\begin{tabular}{|c|c|c|}
\hline Name & Expression & Reference \\
\hline \multicolumn{3}{|l|}{ General model equation } \\
\hline Core radius & $\begin{array}{l}\left(\frac{r_{\mathrm{c}}}{R}\right)^{2}=\frac{1}{1+1.1 F r\left(G_{\mathrm{s}} /\left(\rho_{\mathrm{s}} U\right)\right)^{0.083 \mathrm{Fr}}} \\
\mathrm{Fr}=\frac{U}{(g \cdot D)^{0.5}}\end{array}$ & {$[15]$} \\
\hline Voidage & $\begin{array}{l}\varepsilon=\left(1-\phi_{\mathrm{s}}\right) \varepsilon_{\mathrm{a}}+\phi_{\mathrm{s}} \varepsilon_{\mathrm{c}} \\
\phi_{\mathrm{s}}=\left(\frac{r_{\mathrm{c}}}{R}\right)^{2}\end{array}$ & {$[16]$} \\
\hline \multicolumn{3}{|c|}{ Interface between the fully developed zone and the acceleration zone } \\
\hline Mass flux & $\begin{array}{l}G_{\mathrm{c} \_\mathrm{I}}=\frac{1}{\pi r_{\mathrm{c}}^{2}} \int_{0}^{r_{\mathrm{c}}} 2 \pi r G_{\mathrm{r}} d r \\
G_{\mathrm{a} \_\mathrm{I}}=G_{\mathrm{s}}-G_{\mathrm{c} \_\mathrm{I}} \\
\frac{G_{\mathrm{r}}}{G_{\mathrm{s}}}=a\left[1-\left(\frac{r}{R}\right)^{m}\right]+1-\frac{m a}{m+2} \\
\frac{r_{\mathrm{c}}}{R}=\left[\frac{1}{a}+\frac{2}{m+2}\right]^{\frac{1}{m}}\end{array}$ & {$[17]$} \\
\hline Particle velocity & $\begin{aligned} V_{\mathrm{P} \_\mathrm{cI}} & =\frac{G_{\mathrm{c} \_\mathrm{I}}}{\rho_{\mathrm{s}}\left(1-\varepsilon_{\mathrm{c} \_\mathrm{I}}\right) \phi_{\mathrm{s}}} \\
V_{\mathrm{P} \_\mathrm{a}} & =\frac{G_{\mathrm{a} \_\mathrm{I}}}{\rho_{\mathrm{s}}\left(1-\varepsilon_{\mathrm{a} \_\mathrm{I}}\right) \phi_{\mathrm{s}}}\end{aligned}$ & {$[18]$} \\
\hline \multicolumn{3}{|l|}{ Fully developed zone } \\
\hline Particle mass flux in core and annulus & $\begin{array}{l}G_{\mathrm{c}}=V_{\mathrm{p}, \mathrm{c}} \rho_{\mathrm{s}}\left(1-\varepsilon_{\mathrm{c}}\right) \phi_{\mathrm{s}} \\
G_{\mathrm{a}}=G_{\mathrm{s}}-G_{\mathrm{c}}\end{array}$ & \\
\hline Voidage in core and annulus & $\begin{array}{l}\varepsilon_{\mathrm{c}}=\frac{1}{\pi r_{\mathrm{c}}^{2}} \int_{0}^{r_{\mathrm{c}}} 2 \pi \varepsilon_{\mathrm{r}} r d r \varepsilon_{\mathrm{a}}=\frac{1}{\pi\left(R^{2}-r_{\mathrm{c}}^{2}\right)} \int_{r_{\mathrm{c}}}^{R} 2 \pi \varepsilon_{\mathrm{r}} r d r \\
\varepsilon_{\mathrm{r}}=\bar{\varepsilon}^{0.191+(r / R)^{2.5}+3(r / R)^{11}} \\
\bar{\varepsilon}=\frac{U_{0} \rho_{\mathrm{s}}}{G_{\mathrm{s}} \psi+U_{0} \rho_{\mathrm{s}}} \\
\psi=\frac{U_{0}}{\overline{\bar{\varepsilon} V_{\mathrm{p}}}}=1+\frac{5.6}{F r}+0.47 F r_{\mathrm{t}}^{0.41}\end{array}$ & {$[15,18-20]$} \\
\hline \multicolumn{3}{|l|}{ Acceleration zone } \\
\hline Force balance of particle & $\begin{array}{l}\frac{d V_{\mathrm{p}, \mathrm{c}}^{\prime}}{d z}=\alpha V_{\mathrm{p}, \mathrm{c}}^{\prime}+\frac{1}{V_{\mathrm{pc}}^{\prime}}\left(\frac{\alpha U_{\mathrm{c}}^{2}}{\varepsilon_{\mathrm{c}}}+\beta\right)-2 \frac{U_{\mathrm{c}} \alpha}{\varepsilon_{\mathrm{c}}} \\
\alpha=\frac{3 \rho_{\mathrm{g}} C_{\mathrm{d}}}{4 d_{\mathrm{p}} \rho_{\mathrm{s}}} \\
\beta=\frac{\left(\rho_{\mathrm{g}}-\rho_{\mathrm{s}}\right) g}{\rho_{\mathrm{s}}}\end{array}$ & {$[21]$} \\
\hline Particle mass flux in core and annulus & $\begin{array}{l}G_{\mathrm{a}}^{\prime}=V_{\mathrm{p}, \mathrm{a}}^{\prime} \rho_{\mathrm{s}}\left(1-\varepsilon_{\mathrm{a}}^{\prime}\right)\left(1-\phi_{\mathrm{s}}\right) \\
G_{\mathrm{c}}^{\prime}=G_{\mathrm{s}}-G_{\mathrm{a}}^{\prime}\end{array}$ & \\
\hline Voidage in core and annulus & $\begin{array}{l}\varepsilon_{\mathrm{c}}^{\prime}=1-\frac{G_{\mathrm{c}}^{\prime}}{V_{\mathrm{p}, \mathrm{c}}^{\prime}} \rho_{\mathrm{s}}^{\prime} \varepsilon_{\mathrm{a}}^{\prime}=\varepsilon_{\mathrm{b}}+\left(\varepsilon_{\mathrm{aI}}-\varepsilon_{\mathrm{b}}\right) \lg \left(1+7 x / H_{\mathrm{I}}\right) \\
\varepsilon_{\mathrm{b}}=\frac{U_{0}+1}{U_{0}+2}\end{array}$ & {$[22]$} \\
\hline
\end{tabular}

4. In the acceleration region, a logarithmic voidage profile exists in the annulus (see Eq. 2):

$\varepsilon_{\mathrm{a}}^{\prime}=\varepsilon_{\mathrm{b}}+\left(\varepsilon_{\mathrm{aI}}-\varepsilon_{\mathrm{b}}\right) \lg \left(1+7 x / H_{\mathrm{I}}\right)$

where $\varepsilon_{\mathrm{b}}$ is the bottom voidage at the riser inlet, $\varepsilon_{\mathrm{aI}}$ is the interfacial voidage at the interface of the acceleration region and the fully developed region, and $H_{\mathrm{I}}$ is the height of the acceleration region.

5. For the sake of simplicity, solid velocity is assumed to be constant in the annulus of both the acceleration region and the fully developed region.

The primary model equations adopted in the variable velocity hydrodynamic model are listed in Table 2 . The solution algorithm for these model equations is shown in Fig. 1, which can be implemented with MATLAB code. The tolerance is 0.001 in the calculation of flow field parameters at the interface of the acceleration region and fully developed region. For more details about the implementation of the solution, one can refer to Ref. [14].

\section{Reaction model—six-lump kinetic model [23]}

The selection of the six-lump kinetic model in this study is arbitrary; however, the six-lump kinetic model can offer a couple of advantages. It considers coke and cracking gas as two separate lumps, which makes the prediction of their yields inside the riser available. Besides, the selected six 
Fig. 1 Solution algorithm for the variable velocity hydrodynamics model
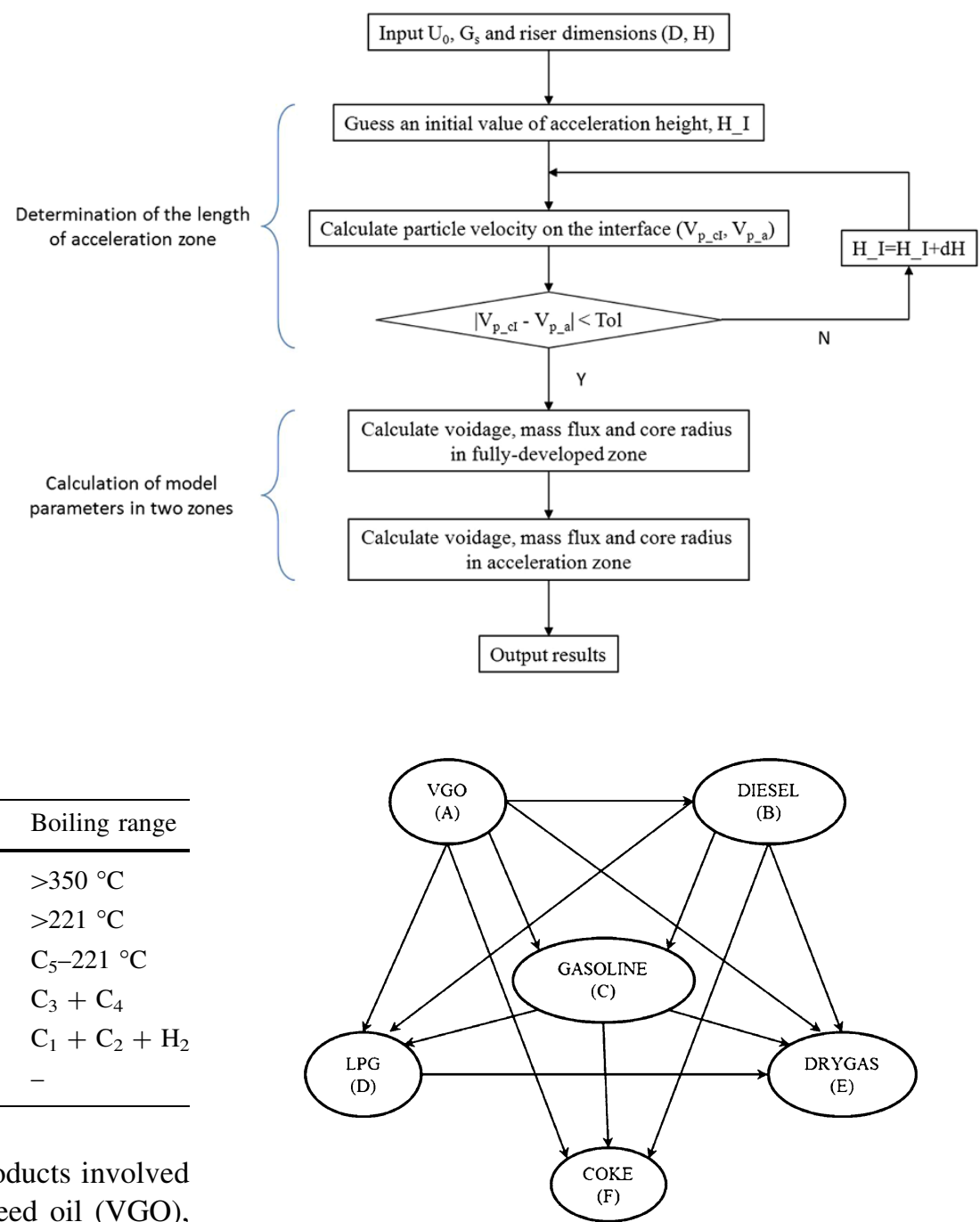

lumps could represent the characteristic products involved in the FCC process correspondingly, i.e. feed oil (VGO), diesel, gasoline, LPG, dry gas, and coke (see Table 3). Moreover, as the main goal of this study is to propose an integrated modeling procedure for FCC riser reactors, the adopted six-lump kinetic model can function well in the justification of the model attributing to the fast simulation and representative final simulated data. Of course, other lump kinetic models can be selected as long as the catalytic reactions inside the riser are properly described with the model.

The reaction scheme is shown in Fig. 2. The reaction rate of lump $i\left(R_{i}\right)$ can be expressed as

$R_{i}=a \cdot R_{\mathrm{CO}} \cdot \sum\left(k_{j} \cdot y_{i}^{m}\right)$

where $R_{\mathrm{CO}}$ is the mass ratio of catalyst to oil. While reactions of converting VGO and diesel into light products are assumed to be second-order reactions, the order $(m)$ of the rest reaction paths is regarded as unit. The effect of catalyst deactivation (a) due to coking on catalysts, nitrogenous poisoning, and Conradson carbon is taken into consideration in the kinetic expression. Besides, $k_{j}$ and $y_{i}$ are the reaction rate constant of reaction path $j$ and mass
Fig. 2 Reaction network of the six-lump kinetic model

fraction of lump $i$, respectively. The calculated kinetic parameters are listed in Table 4.

Construction of the integrated ERN model in Aspen Plus simulator

Unlike other published literatures referring to the modeling of FCC riser reactor, the equivalent reactor network (ERN) model integrating hydrodynamic sub-model, reaction kinetic sub-model, and thermal dynamic sub-model was established in Aspen Plus software. Figure 3 shows the scheme of the modeling framework. In Fig. 3, the hydrodynamic model, based on the variable superficial velocity model presented in Sect. 2.1, was used to construct the ideal reactor/module network in Aspen Plus to reveal hydrodynamics inside the riser. The aforementioned sixlump kinetic model was integrated into the Aspen Plus simulator through external FORTRAN subroutines to describe the reaction behaviors occurring inside the FCC 
Table 4 Kinetic parameters for kinetic model

\begin{tabular}{lllc}
\hline $\begin{array}{l}\text { Path } \\
\text { number }\end{array}$ & $\begin{array}{l}\text { Reaction } \\
\text { path }(j)\end{array}$ & $\begin{array}{l}\text { Pre-exponential } \\
\text { factor }\left(\mathrm{k}_{0}\right)(1 / \mathrm{s})\end{array}$ & $\begin{array}{l}\text { Activation energy } \\
(\text { Ea) }(\mathrm{kJ} / \mathrm{mol})\end{array}$ \\
\hline 1 & $\mathrm{~A} \rightarrow \mathrm{B}$ & 601.7 & 59.33 \\
2 & $\mathrm{~A} \rightarrow \mathrm{C}$ & $2.19 \mathrm{e}+05$ & 95.00 \\
3 & $\mathrm{~A} \rightarrow \mathrm{D}$ & 16.96 & 38.05 \\
4 & $\mathrm{~A} \rightarrow \mathrm{E}$ & 1869 & 176.44 \\
5 & $\mathrm{~A} \rightarrow \mathrm{F}$ & 28.91 & 177.2 \\
6 & $\mathrm{~B} \rightarrow \mathrm{C}$ & 240.46 & 57.5 \\
7 & $\mathrm{~B} \rightarrow \mathrm{D}$ & 46.08 & 141.95 \\
8 & $\mathrm{~B} \rightarrow \mathrm{E}$ & 1560 & 81.78 \\
9 & $\mathrm{~B} \rightarrow \mathrm{F}$ & $2.7 \mathrm{e}+04$ & 174.4 \\
10 & $\mathrm{C} \rightarrow \mathrm{D}$ & 40.39 & 74.22 \\
11 & $\mathrm{C} \rightarrow \mathrm{E}$ & 1.6 & 135.34 \\
12 & $\mathrm{C} \rightarrow \mathrm{F}$ & 1.22 & 44.26 \\
13 & $\mathrm{D} \rightarrow \mathrm{E}$ & 78.98 & 89.27 \\
\hline
\end{tabular}

riser. In addition, the pertinent thermal dynamic model (i.e. BK-10 physical properties method) was coupled with the comprehensive model to character the six pseudo-components in six-lump kinetic model. More detailed integration methods and implementation procedures are elaborated in the following separate sections.

\section{Description of hydrodynamic behaviors using Aspen plus built-in modules}

It is necessary to divide a simulated FCC riser reactor into several compartments, in which the calculation methods have similar properties with the built-in modules in Aspen Plus for the purpose of accurately simulating the catalytic cracking process using Aspen Plus software [24].

In the present study, the flow sheet of FCC reaction system has been described by 13 related built-in modules in Aspen Plus as shown in Fig. 4. It can be observed from Fig. 4 that the whole system includes three sub-systems: feed system, reactor system (i.e. riser reactor), and separation system (i.e. disengager). In the feed system, two modules of heaters (HEATER) have been adopted to represent tubular furnaces that heat feed oil and water. While the disengager has been represented by one module of a separator (SEPGS), the main body of the riser reactor has been described by six modules of continuous stirred tank reactors (RISERD, ANU1-1, ANU1-2, ANU2-1, ANU2-2 and RISERU) and two modules of plug flow reactors (CORE1 and CORE2), which are linked by a splitter module (SPLIT) and a mixer module (MIXER) for splitting and mixing streams among these ideal reactors (i.e. CSTRs and PFRs). Table 5 lists the specific function of each unit module chosen from Aspen Plus database.

Having established an ideal reactor/module network to represent the FCC riser reactor, one must further specify the volume and voidage of each reactor (CSTR or PFR), which are two key parameters to characterize the reactor network for the purpose of reproducing hydrodynamic behaviors reasonably during the simulation. As expected, results obtained from the variable gas velocity hydrodynamic model presented in Sect. 2.1 can provide enough information in the determination of these parameters, which would be elaborated in Sect. 3.1.
Fig. 3 Scheme of the modeling framework

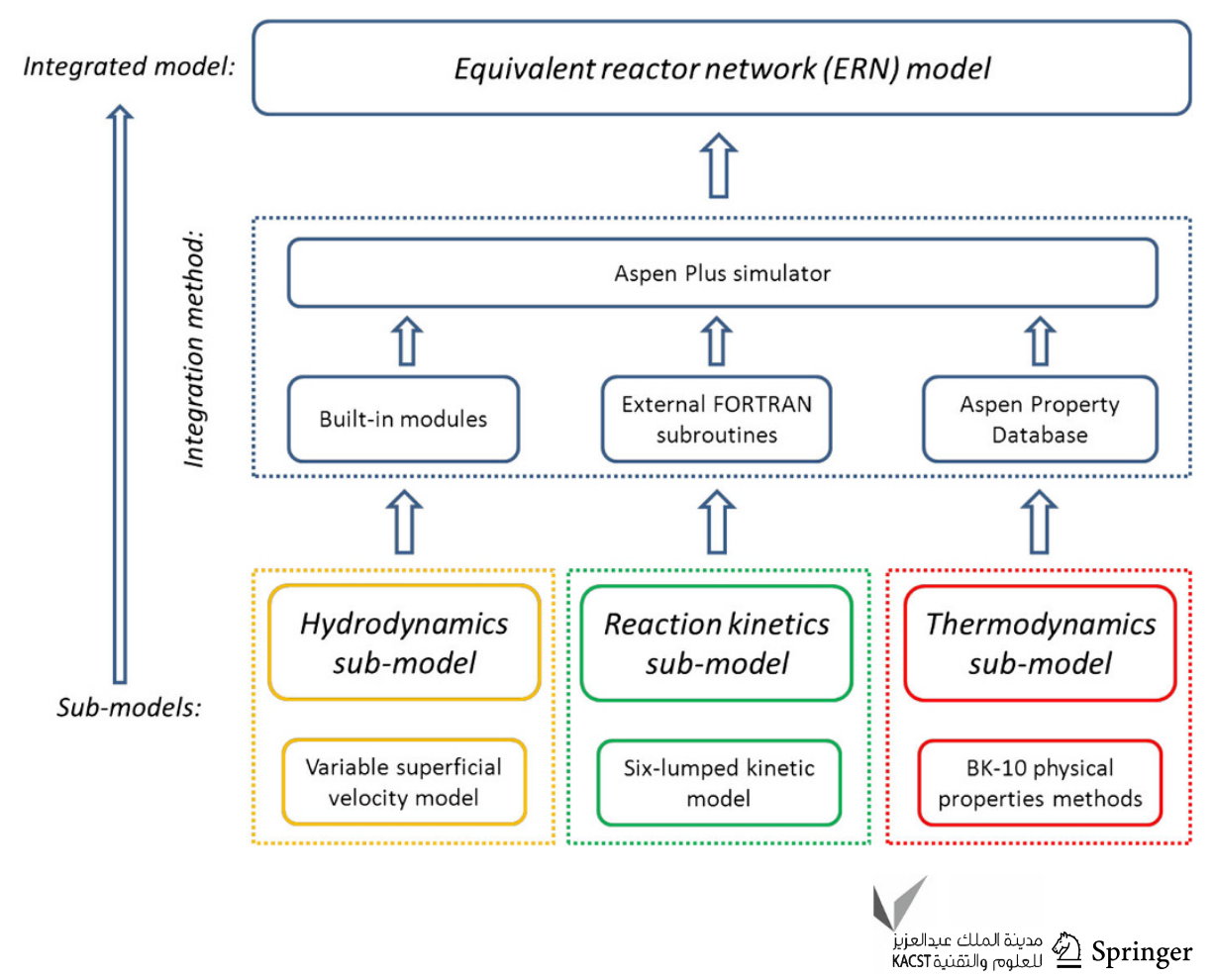


Fig. 4 Schematic diagram for FCC reaction system based on Aspen Plus

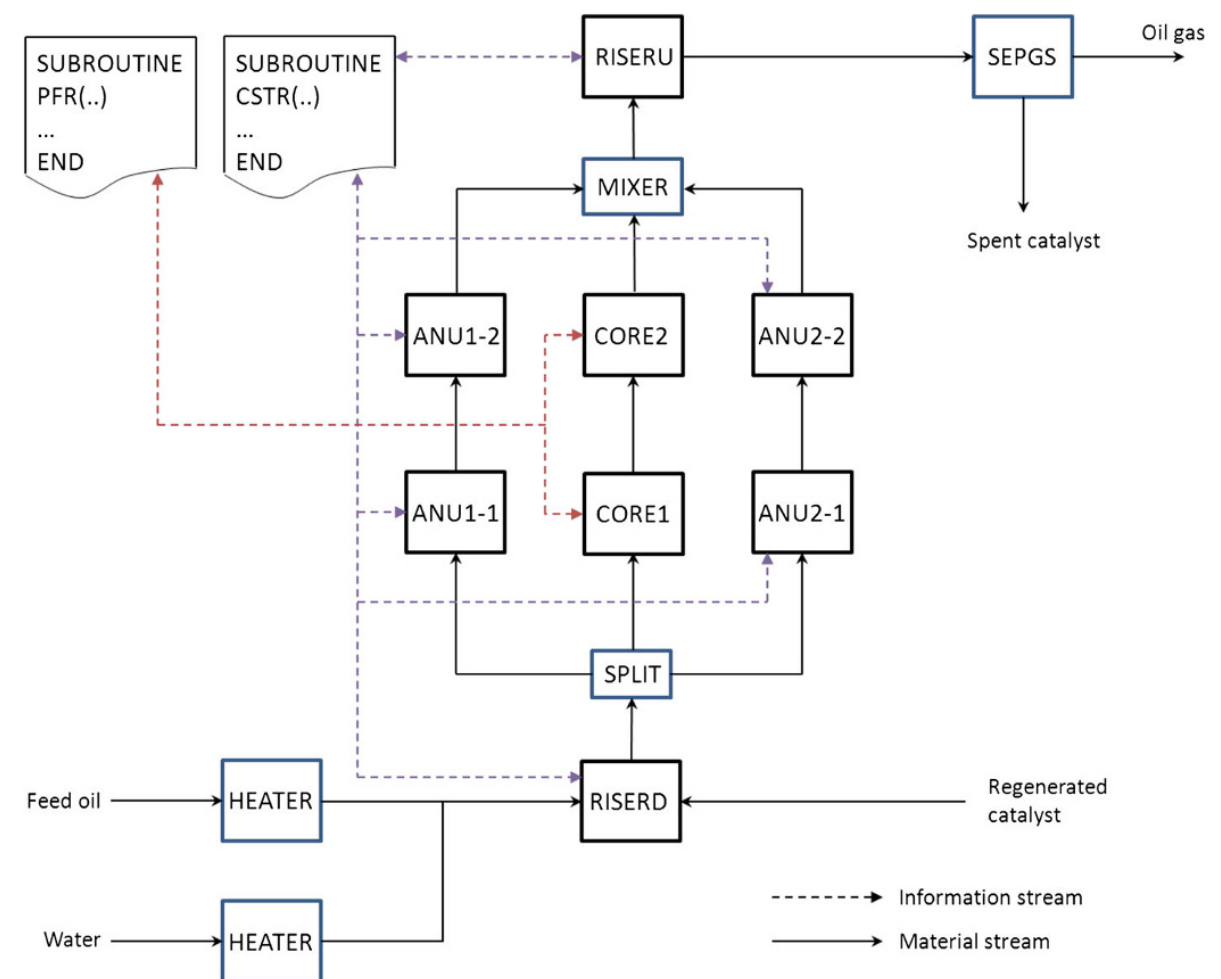

Table 5 Aspen Plus unit modules

Unit Unit type and descriptions

name

HEATER HEATER — heats feed oil and water before they entering the riser reactor

RISERD RCSTR-represents the acceleration zone in the lower part of the riser reactor

SPLIT SSPLIT-splits stream from the acceleration zone to the core and annulus zones

ANU1-1 RCSTR-represents annular zone 1-1

ANU1-2 RCSTR-represents annular zone 1-2

CORE1 RPLUG-represents core zone 1

CORE2 RPLUG-represents core zone 2

ANU2-1 RCSTR-represents annular zone 2-1

ANU2-2 RCSTR-represents annular zone 2-2

MIXER MIXER-mixes streams from the core zone and the annulus zones

RISERU RCSTR - represents the top end of the riser

SEPGS SEP2 - splits spent catalyst from oil vapor

\section{Description of catalytic reactions using external} FORTRAN subroutines

In order to accurately describe the catalytic cracking reactions and predict the yield of each product along the height of the FCC riser reactor, it is necessary to give expressions of reaction rate for all reaction paths presented in the six-lump kinetic model in eight ideal reactors (i.e. six
CSTRs and two PFRs). However, it is not easy work to directly apply the standard data interface in Aspen Plus to describe the reaction rates for these reaction paths. Therefore, an external FORTRAN subroutine is required to link all of the applied reactor modules in Aspen Plus for simulating FCC process. This means eight FORTRAN subroutines in total should be developed in this study for the employed eight ideal reactor modules to exchange data information with the main simulation program of Aspen Plus.

\section{Characterizing six pseudo-components for the six-lump kinetic model}

Since Aspen Plus only provides physical properties of real components, how to characterize each one of the six lumps in kinetic model becomes a tough task. Traditionally, an array of pseudocomponents derived from the True Boiling Point (TBP) characterization curve to represent a lump species could simplify the problem, but there would be a number of disadvantages, e.g. physical properties of pseudo-components could only be estimated by unreliable empirical methods. Alternatively, the main disadvantage of the approach based on pseudo-components can be eliminated if real components were employed to form the substitute mixture for each lump [25]. Of course, the selection of suitable real components and the derivation of the substitute mixture must follow certain criteria and an appropriate algorithm must be defined in consequence. 
Table 6 Real components for six lumps

\begin{tabular}{lllcl}
\hline Lump & $\begin{array}{l}\text { Real } \\
\text { component }\end{array}$ & Alias & $\begin{array}{l}\text { Boiling point } \\
\left({ }^{\circ} \mathrm{C}\right)\end{array}$ & $\begin{array}{l}\text { Molecular weight } \\
(\mathrm{g} / \mathrm{mol})\end{array}$ \\
\hline VGO & n-heptacosane & $\mathrm{C}_{27} \mathrm{H}_{56}$ & 422 & 380 \\
Diesel & n-hexadecane & $\mathrm{C}_{16} \mathrm{H}_{34}$ & 287 & 226 \\
Gasoline & n-octane & $\mathrm{C}_{8} \mathrm{H}_{18}$ & 125 & 114 \\
LPG & Propane & $\mathrm{C}_{3} \mathrm{H}_{8}$ & -42 & 44 \\
Drygas & Methane & $\mathrm{CH}_{4}$ & -162 & 16 \\
Coke & $\begin{array}{l}\text { Carbon- } \\
\text { graphite }\end{array}$ & $\mathrm{C}$ & 700 & 12 \\
& & & \\
\hline
\end{tabular}

In this investigation, the main goal is to propose an integrated modeling procedure for FCC riser reactor; thus, for the sake of simplicity, the following assumption was adopted: all lumps were characterized by real components based on similar boiling point and molecular weight which were chosen from Aspen property database (Table 6). The assumption is somewhat restrictive, but it is necessary because of the lack of information about the physical properties of each lump. If better information is available, then it will always be possible to reproduce the numerical experiments with more accurate results. However, the main goal is expected not to be affected by such simplification.

Physical properties of the related components are calculated by the built-in BK10 method in Aspen Plus, which is suitable for calculating thermodynamic properties of both real and pseudo-components, especially in refinery process [24].

\section{Case study}

In the present study, a ZDT-1 typed pilot FCC unit [26] in State Key Laboratory of Heavy Oil Processing was selected to present how to construct the integrated ERN model and verify the developed process simulation model based on Aspen Plus. The configuration of the riser reactor and main operational conditions are listed in Table 7. Besides, industrial plant data reported by Ali et al. [27] is presented in Table 7 for another case study.

Results of hydrodynamic model and establishment of ideal reactor/module network

As can be observed from Fig. 5, in the lower part of the FCC riser reactor, the gas velocity increases rapidly. And then in the upper part of the riser reactor, the gas velocity continuously increases, but in a moderate manner, which is consistent with the actual production process $[4,28]$. The reason behind this is that the feedstock injection region and some distance above this region are the most intensive reaction zone inside FCC riser reactor [28]. When it comes
Table 7 Operational conditions

\begin{tabular}{|c|c|c|}
\hline Parameters & $\begin{array}{l}\text { Pilot-scale } \\
\text { riser }\end{array}$ & $\begin{array}{l}\text { Industrial riser (Ali et al. } \\
\text { [27] ) }\end{array}$ \\
\hline Riser height $(H)(\mathrm{m})$ & 8.8 & 33 \\
\hline Riser inner diameter $(D)(\mathrm{m})$ & 0.016 & 0.8 \\
\hline Particle density $\left(\rho_{\mathrm{s}}\right)\left(\mathrm{kg} / \mathrm{m}^{3}\right)$ & 1500 & 970 \\
\hline $\begin{array}{l}\text { Particle mean diameter }\left(d_{\mathrm{s}}\right) \\
\quad \text { (um) }\end{array}$ & 76 & 75 \\
\hline $\begin{array}{l}\text { Gaseous phase density }\left(\rho_{\mathrm{g}}\right) \\
\left(\mathrm{kg} / \mathrm{m}^{3}\right)\end{array}$ & 1.3 & 8.4 \\
\hline Gas viscosity $(\mu)$ (Pa.s) & $1.8 \mathrm{e}-05$ & $1.8 \mathrm{e}-05$ \\
\hline Gas inlet velocity $\left(u_{o}\right)(\mathrm{m} / \mathrm{s})$ & 3 & 4.73 \\
\hline $\begin{array}{l}\text { Solids circulation rate }\left(G_{\mathrm{s}}\right) \\
\left(\mathrm{kg} / \mathrm{m}^{2} . \mathrm{s}\right)\end{array}$ & 22 & 286 \\
\hline
\end{tabular}

to the particle velocity, there is a dramatic rise in the acceleration region where catalyst particles are apt to be entrained and accelerated by the expanded oil vapor. As can be seen from Fig. 5, the length of the acceleration region is about $0.5 \mathrm{~m}$. When reaching the fully developed region, the particle velocity levels off close to terminal velocity. Besides, it can be inferred from Fig. 5 that the slip velocity between gaseous phase and particle phase is about two, which is in agreement with the findings of Chan $(\varphi=1.7-2.3)$ [29]. Thus, it can be concluded credibly that the assumed expression of variable gaseous velocity along the riser height (i.e. Eq. 1) in the hydrodynamic model is deemed to be reasonable to describe the phenomenon of gas expansion along the riser height in real FCC process [14].

It is well acknowledged that a crucial issue in exploring core-annulus model is the determination of the core radius. In the present study, core radius along the height of the riser reactor was described according to Paticence and Chaouki model equation [15] and the simulation result was shown in Fig. 6a. As can be seen from Fig. 6a, the core radius is quite large at given operational conditions (configuration of the riser reactor, superficial velocity, and solid flux). This means the volume of the annulus region is relatively quite small and the flow pattern inside the riser reactor is closely approximate to plug flow. Figure $6 \mathrm{~b}$ shows eight regions that the main body of the riser reactor was divided into, including the bottom region (RISERD), lower core region (CORE1), two lower annulus regions (ANU1-1 and ANU2-1), upper core region (CORE2), two upper annulus regions (ANU1-2 and ANU2-2), and the top region (RISERU). It is notable that the determination of the number of regions the riser is divided into and the height of each region is crucial for the reactor/module network in the acquirement of the riser hydrodynamics. In the present study, determinations of these parameters were based on 


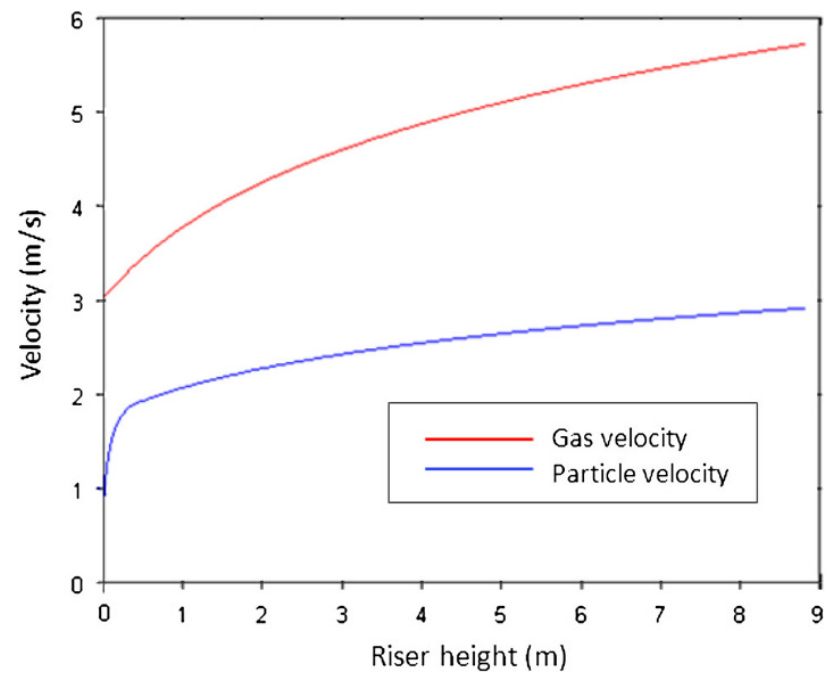

Fig. 5 Gas superficial velocity and particle velocity along the riser height

the height of the acceleration region, core-radius interface along the riser height, and most importantly the agreement of the calculated mean fluid residence time through the reactor/module network and the experimental mean residence time of oil vapor through the riser (since conversion proceeds with residence time in a riser). Through a great many tentative partition schemes, the main body of the riser reactor was eventually divided into eight regions marked with different colors shown in Fig. 6b. The final partition scheme would be justified later in this section after the volume and voidage of each region were obtained. As a matter of fact, the height and volume of each region in Fig. $6 \mathrm{~b}$ can first be estimated and then used to input the volume of each module in the reactor network in Aspen Plus simulator. The calculated height and volume of each region are summarized in Table 8.

Regarding the solid hold-up profile in circulating fluidized bed, while some studies have revealed an axial solid hold-up profile with an inflection point for which it is referred to as the S-profile, other studies indicate that an exponential solid hold-up profile exists with an acceleration zone at the bottom of the riser rather than a dense bed [29]. The type of solid hold-up profile (S-profile, C-profile, exponential profile, etc.) is strongly dependent on gaseous superficial velocity $\left(U_{0}\right)$ and solid circulation rate $\left(G_{\mathrm{s}}\right)$. In this study, $U_{0}$ is in the range of 3-6 m/s and $G_{\mathrm{s}}$ is about $22 \mathrm{~kg} /\left(\mathrm{m}^{2} \cdot \mathrm{s}\right)$, resulting in an exponential solid hold-up profile in the riser reactor. Figure 7 illustrates the axial voidage distribution along the riser height, including voidages in the core and annulus regions, as well as the average voidage along the riser height. From Fig. 7, voidage of each ideal reactor (CSTRs and PFRs) can be inferred and calculated. The estimated values of voidage in each region were listed in Table 8 . The voidage, associated with the volume, of each region were further used to characterize the six CSTRs and two PFRs that made up the main body of the riser reactor.

Having settled the volume and the voidage of each reactor/module, the configuration of the ideal reactor/ module network that represents the main body of the riser reactor was verified by comparing the calculated mean residence time of the fluid which flows through the reactor network with the experimental residence time of oil vapor that flows through the riser. Figure 8 shows the fluid residence time distribution through the established reactor network as well as the comparison between the experimental and calculated mean residence time. As can be seen from the Fig. 8, the fluid residence time distribution curve is rather narrow, this means the calculated residence time for fluid falls in the range of 2.0-2.5 s, indicating a quite approximate plug flow through the established reactor network. Also, as indicated in Fig. 6, the annulus region is quite narrow, which means backmixing flow near the wall of the riser reactor might be neglected, and the assumption of plug flow in the riser can be acceptable. However, the ideal reactor network, established in the present study, could better describe the predominant hydrodynamic behavior than just one PFR which was assumed commonly in real-time simulations of FCC units [7, 8]. Furthermore, the calculated mean residence time of the reactor network is $2.04 \mathrm{~s}$, which quite approximates to the experimental data, $1.98 \mathrm{~s}$. Hence, it can be concluded credibly that the topology of the reactor network that comprises six CSTRs and two PFRs is reasonable to reproduce the hydrodynamic behaviors during the riser simulation in Aspen Plus simulator.

\section{Results and discussion of integrated ERN Model}

Figure 9 reveals the profiles of overall conversion and product yield distribution along the riser height, which were obtained from the proposed ERN model. Inflection points of these lines are at the axial position of $0,0.5,4$, 8.5 , and $8.8 \mathrm{~m}$. As is illustrated, the conversion of VGO sees a dramatic increase initially, and then gradually reaches the peak level of $91.12 \% \mathrm{wt}$, which is strictly close to the experimental data (92\% wt). So is the tendency of gasoline and LPG yields. On the other hand, when turning to the yield of diesel, it increases initially but then slightly declines, which is ascribed to its secondary conversion into lighter products $[4,28]$. Additionally, Table 9 shows the comparison between simulation results and experimental data. It indicates that except for the yield of dry gas, the predicted yields of other products at the riser outlet approximate to the experimental data closely, with a relative error $<6 \%$. 
Fig. 6 a Core radius along the riser height; $\mathbf{b}$ eight regions the riser reactor was divided into

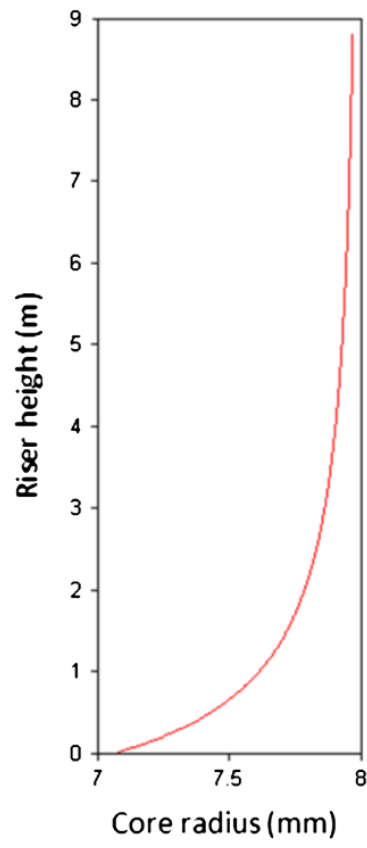

(a)

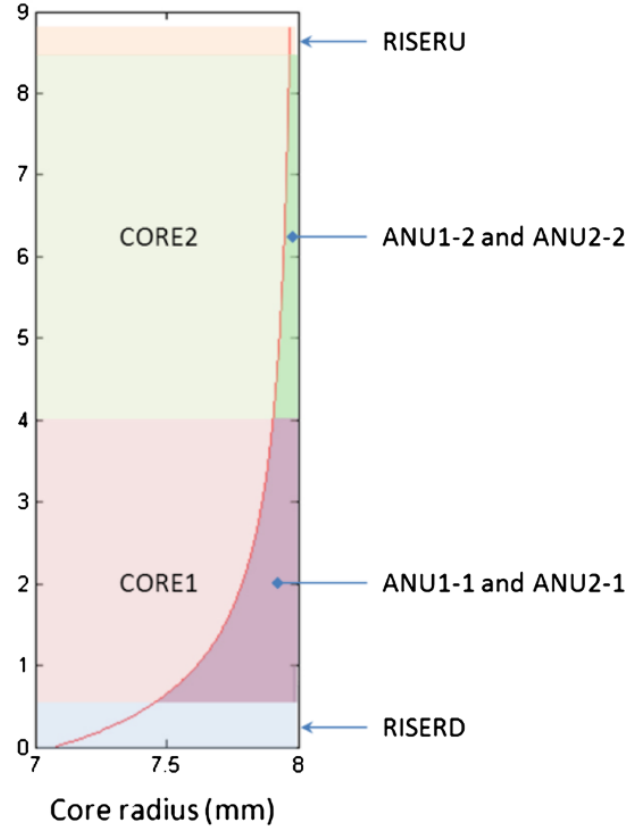

(b)
Table 8 Model parameters for charactering reactor/module network in Aspen Plus

\begin{tabular}{llll}
\hline $\begin{array}{l}\text { Module } \\
\text { name }\end{array}$ & $\begin{array}{l}\text { Height of region } \\
(\mathrm{m})\end{array}$ & $\begin{array}{l}\text { Volume of region } \\
\left(\mathrm{m}^{3}\right)\end{array}$ & Voidage \\
\hline RISERD & 0.5 & $1.0 \mathrm{e}-4$ & 0.979 \\
ANU1-1 & 3.5 & $1.82 \mathrm{e}-5$ & 0.968 \\
ANU1-2 & 4.5 & $6.75 \mathrm{e}-6$ & 0.973 \\
CORE1 & 3.5 & $6.67 \mathrm{e}-4$ & 0.991 \\
CORE2 & 4.5 & $8.90 \mathrm{e}-4$ & 0.993 \\
ANU2-1 & 3.5 & $1.82 \mathrm{e}-5$ & 0.968 \\
ANU2-2 & 4.5 & $6.75 \mathrm{e}-6$ & 0.973 \\
RISERU & 0.3 & $6.0 \mathrm{e}-5$ & 0.992 \\
\hline
\end{tabular}

Apart from the pilot scale riser reactor, a case study on an industrial scale plant was carried out with the same procedure of building ERN model for pilot scale risers. It should be noticed that other suitable hydrodynamic submodel and kinetic sub-model were re-developed. However, the implementation procedure and methods used during the construction of the integrated ERN model remained the same. Figure 10 shows the comparison between model prediction and plant data for gasoline and coke at the riser outlet. As can be seen from Fig. 10, model predictions of the product yield distribution at the riser outlet matches satisfactorily with the plant data.

In sum, the referred comparison could lead to the firm conclusion that the equivalent reactor network (ERN) model can simulate the FCC riser reactor credibly and give rise to desirable results. Moreover, the ERN model can perform the steady-state simulation of FCC process in only

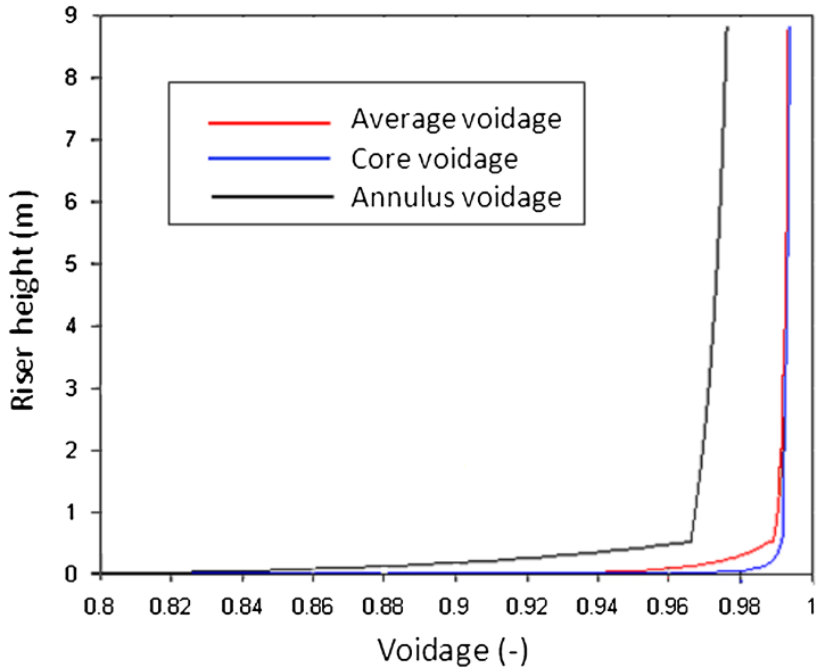

Fig. 7 Voidage distribution profile along the riser height

several seconds on a single desktop personal computer, compared to multiple days/months on multiple processors for more detailed CFD-based simulations [4-6, 13].

\section{Conclusion and outlook}

Aiming at the confliction between model accuracy and model computation time during the modelling of FCC riser reactors, a novel integrated model, named equivalent reactor network (ERN) model, was developed. The constructed ERN model, based on the proposed integration methodology, coupled the hydrodynamic model, kinetic 


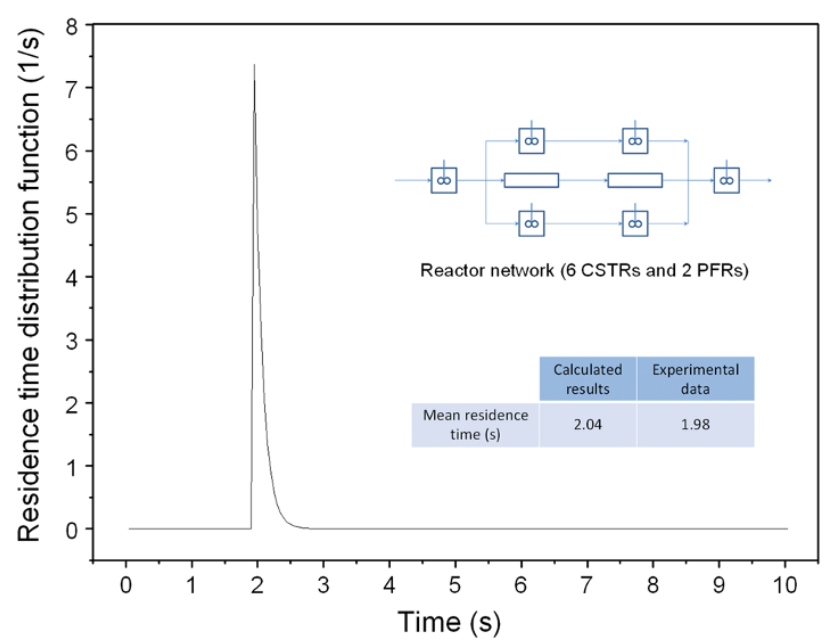

Fig. 8 Fluid residence time distribution through the established reactor network

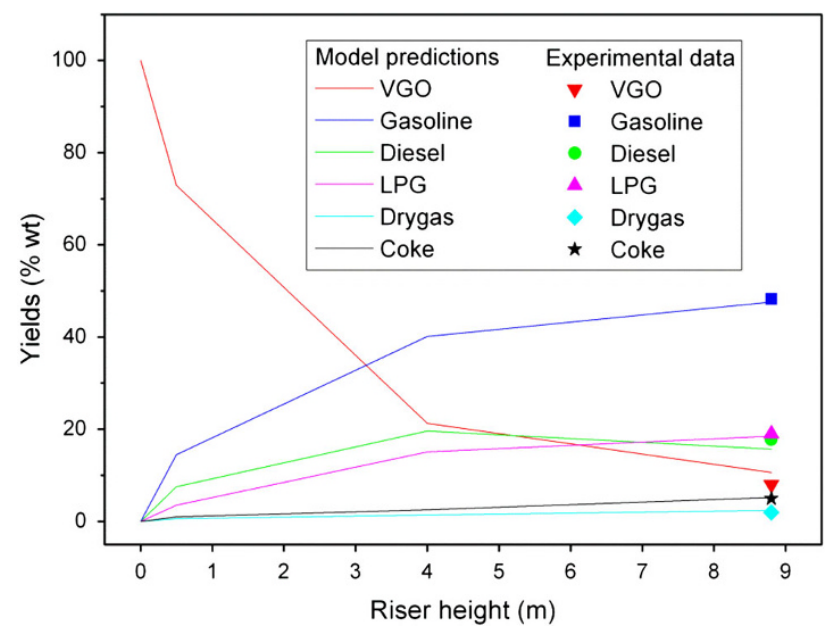

Fig. 9 Product yield distributions along the riser height

model, and thermodynamic model all together in a process simulator (namely Aspen Plus). Two case studies on a pilot-scale riser and an industrial-scale riser were carried out to show the implementation process of the proposed ERN model.

Numerical findings demonstrated that the integrated ERN model is capable of predicting the overall conversion and product yields along the riser height. The model results are in close agreement with the experimental data from the pilot-scale riser and industrial data reported in the literature. Moreover, the time-efficient computation of the integrated ERN model in steady-state simulations for FCC riser reactors would make it possible to carry out other advanced studies, such as real-time dynamic simulation, optimization, and control of FCC units.

Future investigations can be carried out to improve and perfect the integrated model, such as the optimization of
Table 9 Comparison between simulation results and experimental data

\begin{tabular}{|c|c|c|c|c|}
\hline \multirow[t]{2}{*}{ Items } & \multirow{2}{*}{$\begin{array}{l}\text { Numerical } \\
\text { results }\end{array}$} & \multirow{2}{*}{$\begin{array}{l}\text { Experiment } \\
\text { data }\end{array}$} & \multicolumn{2}{|l|}{ Error } \\
\hline & & & Absolute & $\begin{array}{l}\text { Relative } \\
(\%)\end{array}$ \\
\hline $\begin{array}{l}\text { Mix temperature } \\
\left({ }^{\circ} \mathrm{C}\right)\end{array}$ & 548 & 548 & & \\
\hline $\begin{array}{l}\text { Reaction } \\
\text { temperature }\left({ }^{\circ} \mathrm{C}\right)\end{array}$ & 515 & 515 & & \\
\hline $\begin{array}{l}\text { Ratio of oil to } \\
\text { catalyst }\end{array}$ & 8.0 & 7.97 & & \\
\hline Residence time (s) & 2.04 & 1.98 & 0.06 & 3.03 \\
\hline Conversion (wt \%) & 91.12 & 92 & -0.88 & 0.96 \\
\hline \multicolumn{5}{|c|}{ Product yield (wt \%) } \\
\hline VGO & 8.88 & 8 & 0.88 & 11 \\
\hline Diesel & 16.83 & 17.8 & -0.97 & 5.44 \\
\hline Gasoline & 48.96 & 48.3 & 0.66 & 1.36 \\
\hline LPG & 18.64 & 19.02 & -0.38 & 1.99 \\
\hline Drygas & 1.61 & 1.95 & -0.34 & 17.4 \\
\hline Coke & 5.08 & 4.93 & 0.15 & 3.04 \\
\hline
\end{tabular}

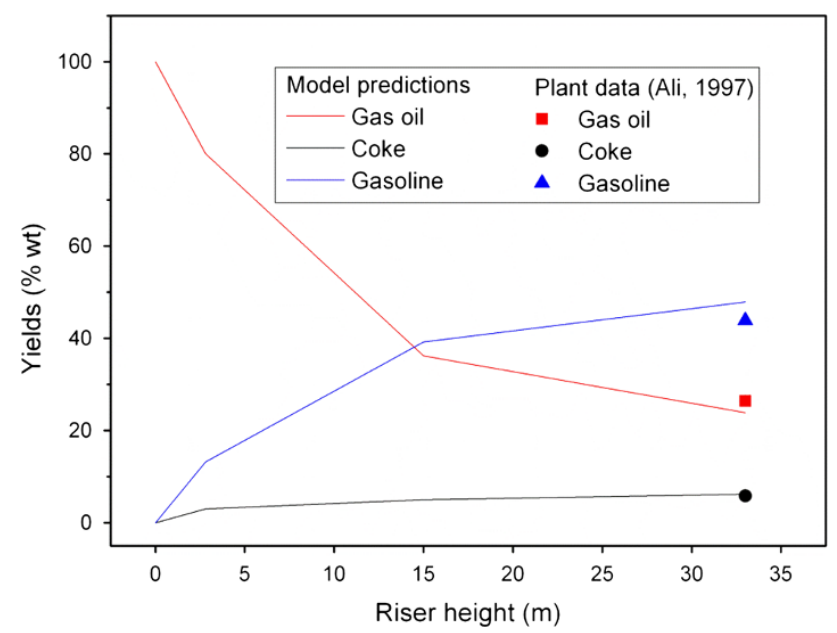

Fig. 10 Model predictions compared with industrial plant data reported by Ali et al. [27]

model parameters to better characterize the reactor/module network in the integrated ERN model. Parameters including the volume and voidage of each region, the number of regions the riser reactor should be divided into, as well as the verification of the established reactor network still need to be emphasised upon.

Acknowledgments The authors are grateful to the National 973 Program of China (No. 2012CB215006) for the financial support.

Open Access This article is distributed under the terms of the Creative Commons Attribution License which permits any use, distribution, and reproduction in any medium, provided the original author(s) and the source are credited. 


\section{References}

1. Pinheiro CI, Fernandes JL, Domingues L, Chambel AJ, Graca I, Oliveira NM, Ribeiro FR (2011) Fluid Catalytic Cracking (FCC) process modeling, simulation, and control. Ind Eng Chem Res $51: 1-29$

2. Gupta RK, Kumar V, Srivastava VK (2010) Modeling of fluid catalytic cracking riser reactor: a review. Int J Chem React Eng $8: 1-40$

3. Duan LW, Xue GP, Weng HX (2010) Research progress of lump kinetic model of fluid catalytic cracking. Chem Ind Eng Prog 29:22-27

4. Gao J, Xu C, Lin S (1999) Advanced model for turbulent gassolid flow and reaction in FCC riser reactors. AIChE J 45:1095-1113

5. Dutta A, Constales D, Heynderickx GJ (2012) Applying the direct quadrature method of moments to improve multiphase FCC riser reactor simulation. Chem Eng Sci 83:93-109

6. Gan J, Zhao H, Berrouk A, Yang C, Shan H (2011) Numerical simulation of hydrodynamics and cracking reactions in the feed mixing zone of a multi-regime gas-solid riser reactor. Ind Eng Chem Res 50:11511-11520

7. Zhang J, Wang Z, Jiang H, Chu J, Zhou J, Shao S (2013) Modeling fluid catalytic cracking risers with special pseudo-components. Chem Eng Sci 102:87-98

8. Han I-S, Chung C-B (2001) Dynamic modeling and simulation of a fluidized catalytic cracking process. Part I: process modeling. Chem Eng Sci 56:1951-1971

9. Quintana-Solorzano R, Thybaut JW, Marin GB, Lodeng R, Holmen A (2005) Single-event micro-kinetics for coke formation in catalytic cracking. Catal Today 107-108:619-629

10. Lee JH, Kang S, Kim Y (2011) New approach for kinetic modeling of catalytic cracking of paraffinic naphtha. Ind Eng Chem Res 50:4264-4279

11. Zhu C, Jun Y, Patel R, Wang D, Ho TC (2011) Interactions of flow and reaction in fluid catalytic cracking risers. AIChE $\mathrm{J}$ 57:3122-3131

12. Deng R, Wei F, Liu T, Jin Y (2001) Radial behavior in riser and downer during the FCC process. Chem Eng Process 41:259-266

13. Lagaer P (2006) Simulation of fluid catalytic cracking with single-event micro-kinetics and computational fluid dynamics. M.S. Thesis, University of Ghent, Belgium
14. Xia SH (2010) Coupled simulation of flow and reaction in reaction and regeneration system of FCC. M.S. Thesis, China University of Petroleum, Dongying

15. Patience GS, Chaouki J (1993) Gas phase hydrodynamics in the riser of a circulating fluidized bed. Chem Eng Sci 48:3195-3205

16. Pugsley TS, Berruti F (1996) A predictive hydrodynamic model for circulating fluidized bed risers. Powder Technol 89:57-69

17. Rhodes MJ, Sollaart M, Wang XS (1998) Flow structure in a fast fluid bed. Powder Technol 99:194-200

18. Zhang W, Johnsson F, Leckner B (1995) Fluid-dynamic boundary layers in CFB boilers. Chem Eng Sci 50:201-210

19. Lim KS, Zhu JX, Grace JR (1995) Hydrodynamics of gas-solid fluidization. Int J Multiphase Flow 21:141-193

20. Kunii D, Levenspiel O (1991) Fluidization engineering. Butterworth-Heinemann, Boston

21. Nieuwland JJ, Delnoij E, Kuipers JAM, Van Swaaij WPM (1997) An engineering model for dilute riser flow. Powder Technol 90:115-123

22. King DF (1989) Estimation of dense bed voidage in fast and slow fluidized beds of FCC catalyst. Fluidization VI: 1-8

23. Guo JH (2008) Primary Study of the lumped kinetic model for heavy oil cracking into propylene by two-stage-riser technology. M.S. Thesis, China University of Petroleum, Dongying

24. Aspen TI (2009) Aspen Plus user manual and guide. Burlington, MA

25. Eckert E, Vaněk T (2005) New approach to the characterization of petroleum mixtures used in the modelling of separation processes. Comput Chem Eng 30:343-356

26. Zhang JH, Shan HH, Liu WJ, Li CY, Yang CH (2013) Synergistic process for coker gas oil catalytic cracking and gasoline reformation. Energy Fuels 27:654-665

27. Ali H, Rohani S (1997) Dynamic Modeling and Simulation of a Riser-Type Fluid Catalytic Cracking Unit. Chem Eng Technol 20:118-130

28. Shan HH (2004) Fundamental studies on the technology of fluid catalytic cracking with two-stage risers. Ph.D. Thesis, China University of Petroleum, Dongying

29. Chan CW, Seville JP, Parker DJ, Baeyens J (2010) Particle velocities and their residence time distribution in the riser of a CFB. Powder Technol 203:187-197 